\title{
Social motion
}

\author{
M. Despang ${ }^{1,2}$ \& E. Mumm ${ }^{1}$ \\ ${ }^{I}$ College of Architecture, University of Nebraska, Lincoln, USA \\ ${ }^{2}$ Despang Architekten Hannover, Germany
}

\begin{abstract}
Urban transportation is mainly seen as a challenging engineering and logistical task. However, the results of technically-installed infrastructure become part of the urban fabric, structured tectonics and, in the best case, architecture for short occupancy. In regard to the early 20th century philosopher Ludwig Wittgenstein, for whom architecture was "like a gesture and unlike every movement of the human body is a gesture, neither is every building architecture", the question remains as to how the infrastructural environment needs to perform beyond its primary function. This paper will illustrate how an architectonical approach on infrastructure can catalyze the social impact of infrastructural enterprises. Achievements of socially-responsive infrastructures will be demonstrated by two intercontinental case studies: the rethinking of the "Loop" in Chicago Illinois USA by graduate student Erin Mumm and the light rail station projects in Germany by her mentor Professor Martin Despang. In a collaborative way the authors Mumm and Despang, with his practice base in Hannover, Germany and his research and teaching platform at the College of Architecture in Lincoln, Nebraska, USA, will point out the potential of specific architectural treatment in achieving an economical and social win/win affect. The study concludes that giving infrastructural concepts multiple meaning beyond the primary purpose of moving people can hopefully result in high public acceptance, which is the most fundamental requirement for a sustainable future of infrastructural investments. The paper presentation will point out the societal and economical challenges and the potential of architecturally-engineered infrastructure.

Keywords: infra/structural architecture, light rail systems, urban trains, elevated transportation, sense of place, infrascape.
\end{abstract}




\section{Introduction and analysis}

To move people collectively rather than individually has always been crucial to urban territory. Starting in the mid-to late $19^{\text {th }}$-century, transportation by rail enabled a logistical flow of goods and people in the growing urban areas.

In Europe, the layout of transportation systems had to be implanted upon century's old urban landscapes. This idea was soon exported and easily integrated into new American cities due to their efficient and strategic grid. In the mid-to late-20th century the predominance of the car as the far less effective individual transportation means prevented urban light rail systems from surviving in moderately sized cities. In the metropolis or megalopolis the urban light rail systems remained the primary artery for keeping the population in motion all year long, some of them to the extent that it was impossible to upgrade. While their surroundings were changing, they continued to deteriorate like aged, roaring dragons from ancient times, as is the case with the elevated ('El') train system in Chicago, Illinois, USA, specifically within the "Loop". Many of these systems are major icons within their respective cities, such as the previously discussed 'El' and the Metro in Paris. However, financial burdens for maintenance of these systems have become another reason for their neglected appearances and has delayed any renovations or suitable updating that would be needed for them to sustain themselves.

Nevertheless the urban light rail is celebrating a revival because it is still the most technologically reasonable and viable infrastructural concept. Many midsized American cities were born upon the railroad tracks as they arose westward throughout the United States. City administrators spent the late $19^{\text {th }}$ and early $20^{\text {th }}$ century building trolley systems to ease traffic in their growing cities. The majority of these would soon be demolished with the popularity of the automobile. However, many cities, such as the nearby Omaha, Nebraska, are currently debating a possible reinstallation of their downtown trolleys.

When the EXPO 2000 was planned for Hannover, Germany, the city took the opportunity to extend the infrastructure to bridge, so far, unconnected neighbourhoods which led to the fairground fields. To become at all possible, all cases of the project needed some careful fundamental consideration beyond the infrastructural and engineering scope, due to an almost ironic societal phenomenon. Despite the many benefits provided for the entire city and its population, such as, barrier free accessibility and connectivity, infrastructure is often one of the most abused, disliked, and mistreated building types. They tend to lack the protection of private belonging and are considered fair game.

This raises the sociological and psychological question of an investigation into the reasons. This presentation will point out possible strategies for improvement by means of contemporary cutting edge architectural conceptualization, development, and execution; as opposed to restorative strategies, which only build upon sentimentally reactivating the memory of the past by creating vehicles and structures resembling an earlier era of urban trolleys. 


\section{German case studies}

The train stations in Hannover, Germany serve as a good case study to understand the societal and economic relevance these structures could potentially provide. Hannover, in the 1970s, committed itself to a system with lowered tracks in the underground, which resulted in the necessity for elevated train stops on the ground. Although the stations use ramps to provide accessibility for the elderly, the physically handicapped, and parents with strollers, the structures are often seen as a physical hindrance congesting the streetscape. Due to the tight existing street profiles, the stations literally have to be squeezed into the existing infrastructure. For the public train users this means they are within uncomfortable proximity to the heavy street traffic. Therefore the commonly built dam-like structures topped with uniformed glass huts tend to be left abandoned and as a result of this they become targets for further routine serial vandalism. The final means of deterioration stems from an endless lack of financial resources to maintain it. The design of the 13 stations for the D-Line in Hannover took this research into careful, serious consideration and proposed a strategic custom-made solution which convinced the jury of the architectural competition in 1996. The 70 meter long platforms are steel structures, which span over individually placed prefabricated concrete foundations. This design allows for the existing streetscape and views to continue uninterrupted, and, as well, permits light weight trash to pass underneath rather than collecting around the station.
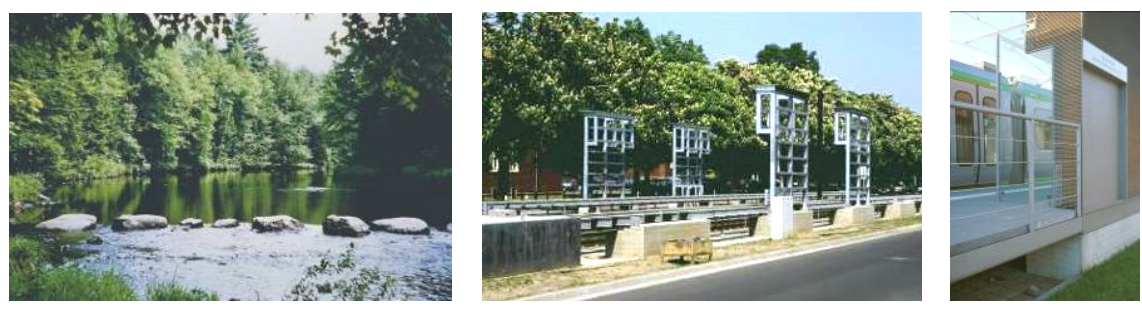

Figure 1: $\quad$ Urban tectonic strategy of Hannover light rail train stations $[4,5]$.

On top of several foundation blocks sit "waiting blocks", three dimensional plasticized volumes, which are tailored to be wide and protective devices placed parallel to traffic. The blocks contain all of the technical functions for the facility integrating many features in a flush manner which helps to prevent them from being affected by vandalism. The blocks are differentiated and articulated in several ways with many different functions, such as, sitting, standing, information, et cetera. The sculptural subtractive treatment of the block volumes provides protective space, which creates a sense of place for a short time. Weather protection is integrated by using a tarpaulin material which is buttoned onto a glass screen. The blocks are each double shell sheathed; however, their similarities vary through the use of different material applications. These materials are chosen in response to the specific surroundings of each station in an 
interpretative and non-literal way. The materiality identifies with the specificity of the site context and choreographs a subtle transition for the travelling passenger from the station to their next destination. It also engages and interacts with the individual in a way that stimulates personal memories. The project has been honoured with several international awards [4] and has been widely published in Europe, Asia and the USA [5], however, the best compliment has always been the appreciation by the users on a local level.
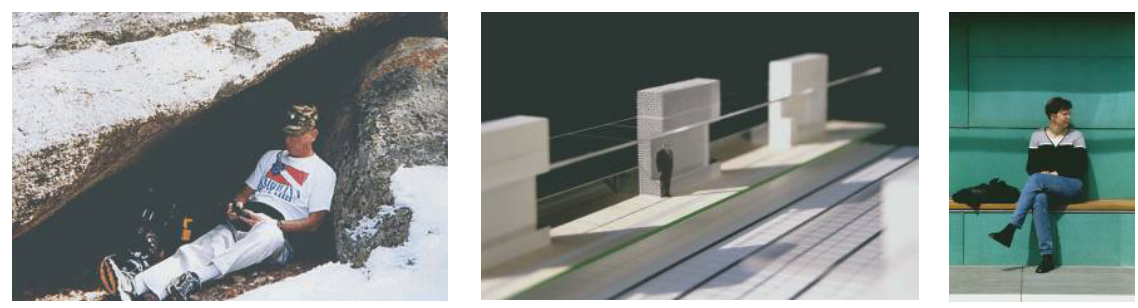

Figure 2: Event-spatial-formal evolution of the Hannover "waiting blocks".

It is important to be aware that projects like this would not be possible without the collaboration of engineering partners, in this case Christian Fahlke, light designer, Uwe Dettmer and Dr. Burmester, structural engineers, and the Düsseldorf office of ARUP. In Hugh Collis's book "Transport, Engineering and Architecture", Sir Ove Arup is quoted "what the engineer sees as structure, the architect sees as sculpture, actually, of course, it is both" [6]. Collis adds "collaborations between ARUP and leading architects such as Norman Foster and Renzo Piano/on Stansted and Kansai airports have placed the forefront of developments in transport design. However Guenther and Martin Despang's light rail system demonstrates that the transport sector also provides opportunities for architects in small firms to display their skills and opportunities". Collis, who unfortunately passed away shortly after working on this book, was a major contributor to this forefront. Through his pleas, he both encouraged and influenced Despang Architekten to continue the street work in the world of proletarian infrastructure.
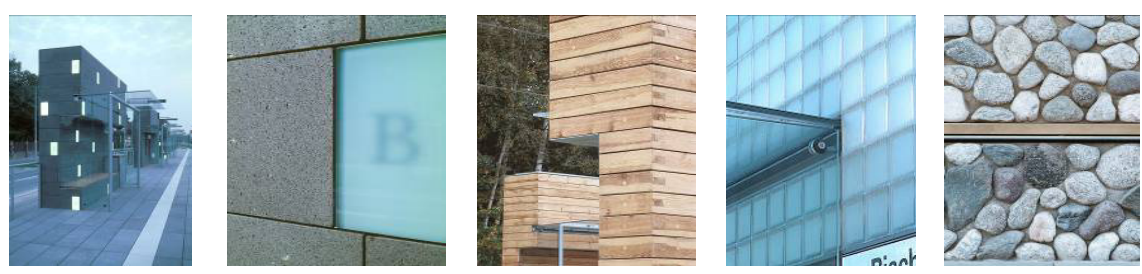

Figure 3: Site specific materializations of the Hannover "waiting blocks".

This led to a series of three related projects. The first is the design for a new "green" light rail line in Karlsruhe, Germany. The circumstances for this project were considerably different because the customized design strategy started from a different point. 
Ironically, the attitude against this infrastructural typology was the initial starting point based upon the existing city structure and plan. The northern part of the Karlsruhe baroque city master plan featured radial infrastructural paths through a forest, which the city was about to expand upon. There was one obtrusive diagonal line, a railroad track, which would become a green space during the urban conversion. The city and the light rail company proposed that the new rail network be placed in similar accordance with the former one; however, the new line would follow a linear path along the green park space, rather than splicing through it diagonally. This resulted in sharp opposition from the residents leading the city to request the help of architects. The condition of low entry level trains enabled the design proposal to have minimal environmental affects or hindrances. The design and materials consist of a layer of alternating wood and stone slats which rest on steel I-beams and are then fixed to individual concrete foundations. The stone is raised slightly higher to guarantee a good, anti-slippery grip.
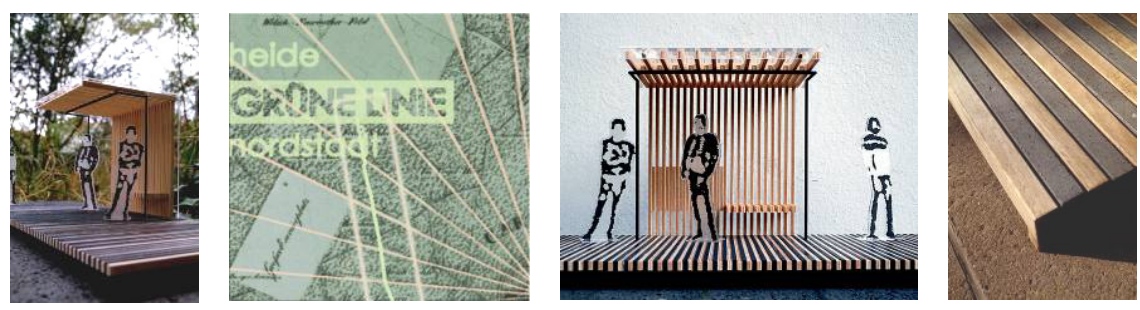

Figure 4: Depicts the wood-stone sliced "green line".

The wooden shelter structure unfolds in a tectonically interlocking manner out of the platform and is sheathed with a glass coating. The structural tectonic alteration of the profiles allow for a semitransparent enclosure, which at the same time is protective and allows good visibility. Wood, normally considered an inappropriate material for this building type, is strategically applied in a way that is least likely to be vandalised as it is camouflaged by the natural surroundings. Compatibility with the other materials makes it tougher and lets it survive in the urban jungle.

This project evolved into the following project, which consists of shelter design to protect subway access ways in the city of Bochum, Germany. Here once again the development of an architectural investigation was seen as a successful strategy for a sustainable infrastructural enterprise. This project began by researching and gaining insight about the accelerating damage done to the escalators, as they have had prolonged exposure to rain and natural elements. A covering structure was estimated to be cost efficient in the long run and an architectural competition was initiated. The winning design by Despang Architekten proposed a screen of steel blades as continuous wall and roof structure which cantilevers over a steel beam. Under the circumstances of high vehicle impact loads, the materialization in steel with a repetition of thin 
members allows to retain a light notion. The screen smoothly regulates the adjustment to the light, coming from the underground dark emerging into the daylight.
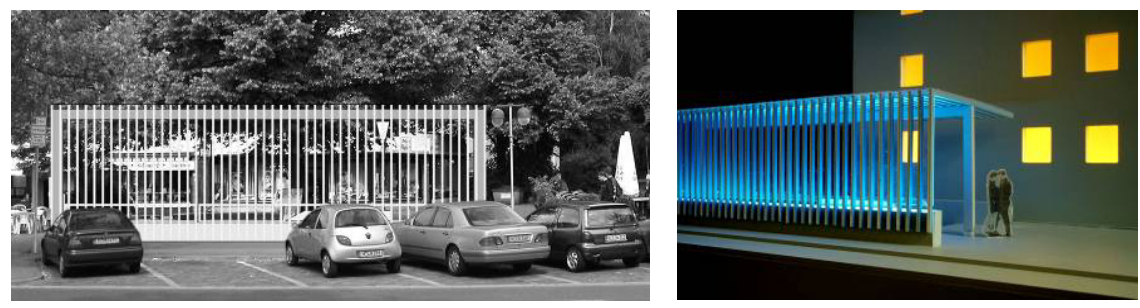

Figure 5: Steel ribbon beacon design in Bochum, Germany.

An important element, once again, is the lighting design. Here, a simple linear line of blue fluorescent lamps were aligned across the bottom of the structure. The rectangular steel tube blades are powder coated in white, with the exception of the side facing the entrance, which are coated in blue. This very simple and durable system results in an intriguing light sculpture; which in relation to the movement of the traffic will likely change its appearance throughout the day.

The last example shows these research strategies applied to a much smaller scale project: digital signposts for the Karlsruher Verkehrsbetriebe light rail network stations [7]. This represents that the notion of social and economically responsive design is not a matter of scale but again of the tripartite mission of architectural conceptualization, development and execution. The given design task was originally as simple as finding an appropriate way to hold up a given digital info box on the train stations. This could basically be resolved by pure engineering means as it has been done before, by erecting a metal post, attaching a cantilevered extension arm and suspending the box from it. Once again, a comprehensive research investigation into the events and resulting demands around the object led to schematic design explorations with the holistic approach that the element would become a service point on the platform.

A variety of additional needs were identified, such as considering that older passengers might not be able to see the variety of digital displays at all times and might still require the traditional analogue displays. Also, the experience illustrated that there was an increasing desire for safety- well lit spaces and service that allows users to call for help in emergency situations. The integration of this research criteria resulted in the concept of a meandering steel band. This allowed the functions to be embedded within the winding pattern, which alternates between solid function-boxes and sponsored glass display boxes. The final winding piece cantilevers over the platform and displays the information box. This prototype was then physically reduced to its most quintessential minimum. The result was the post and cantilever becoming a standardized U-steel profile. The closed back protects it from the rear car traffic, whereas the open side faces the user on the platform and is filled in with softer, more tangible 
brass sheathing. This material covers up the complex variety of functional components contained within a slim nine $\mathrm{cm}$ deep box, which was a major design challenge to attain.

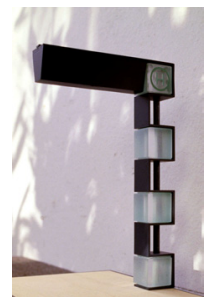

Figure 6:
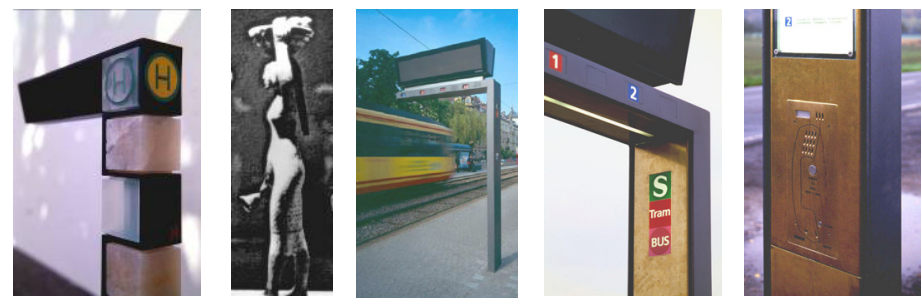

Since expensive technical service components often have the highest potential of being vandalized, a considerable amount of time was spent on research and design, while mock ups were also constructed to understand the details. The time table displays are frameless and installed with flush glass plates, which do not allow for vandalism from tools like pocket knives. The emergency calling units were designed in collaboration with "Racal", a manufacturer, which prototyped a laser cut brass aperture which has been etched to provide a pre patinated quality. The great advantage of brass is the smooth, easy to clean, antigraffiti surface. The material has self healing abilities in restoring the protective patina in case of mechanical vandalisation like scoring with a key. Stainless steel was not an option for this application because the abraded base metal particles would corrode and look unpleasant. After considering human behaviour in certain events it was realized that a person needing help might need a place to rest, which resulted in an emergency seat. It is operated by a spring and after being used flips backs into the upright position, flush with the lid. In the cantilevered beam, Dr. Burmester resolved the complicated structural stiffening of the corner to the post and water blasted cut outs were used to fill the illuminated analogue signs. The most prevalent innovation is that the info box sits on top of the cantilevering beam, instead of like "wet laundry on the clothesline", as is the case with the dropped hanging version. In this way the structure is more "ergonomically" thoughtful, in relationship to cultures where human beings prefer to carry heavy loads by balancing them on their head. Additionally the tectonics result in a gesture, not unlike serving up something on a plate, which represents the motivation of the client to provide better service to the passenger. The ceiling lid incorporates a linear light fixture, which washes down along the brass filling and secures the safety issue by creating a sense of place under and around the small object.

In all mentioned case studies, it is demonstrated, that infrastructural architecture is not design that wants to compete with its surrounding context but rather to spatially and formally generate itself in a sensual way specifically and unobtrusively with the multifunctional needs and events of public frequency. 


\section{USA case study}

A similar holistic approach of architectural engineering with social and economical coherence is examined in the current design thesis project of Erin Mumm, however, at a much larger scale [9]. Apart from adding new structures and program, her focus is related to the treatment of technically outmoded objects. Unlike historic preservation, where the building substance can be stripped and technologically updated, this is usually impossible in the case of the infrastructural building type. This is because the constant usage by passengers wears down the structural integrity and also, it is not economically reasonable. Mumm's project investigates a way out of this dilemma by combining architectural strategy with interdisciplinary multi-coding of meaning and functioning.

The key to maintaining funding for infrastructure, specifically mass transit, is to maintain a consistent rider-ship from the citizens it serves and to be creative in the tactics of funding. However, it is firstly important to understand how to sustain rider-ship, or the whole system will fail. This project, "In the Loop", investigates how architectural design can be integrated with engineering to create a system in which residents are excited about using mass transit. Transportation facilities are compelling architectural structures because they are not built as a destination but rather as a facilitator toward its inhabitant's destination and they allow interaction from people of all backgrounds. Because these facilities are not considered destinations, their upkeep is often neglected and architectural aesthetic is not always a major concern for their design. This is most likely due to the fact that these structures are funded by the government and as long as they continue to function at their mediocre pace, authorities find no reason to improve upon it. However these public spaces become part of the fabric of a city and it would be beneficial for them to function as a more sustainable and aesthetically pleasing environment. Chicago's 110-year old elevated train system inspired this project due to its severe dilapidation and its iconic association with the city it serves. The Loop, the core of the city, was chosen as the focus because of the area's revitalization, its high volume of inhabitants, its plethora of cultural settings, and the opportunities it provides for additional public program abounding the proposed infrastructure.

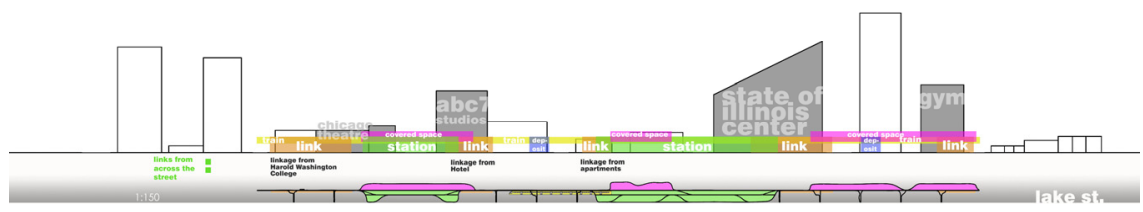

Figure 7: Elevation depicting concept of station below, public path above.

As stated previously in Despang's examples, there is currently a revival in the construction and rehabilitation of infrastructure in large part due to the growing depletion of energy resources. An interesting project in New York City called the High Line, is currently under construction and has expanded upon the 
programmatic functions of infrastructure. Although the project does not incorporate any mode of public transport, it is implemented upon an abandoned elevated rail line on the West side of Manhattan running a distance of 1.5 miles. Many of the world's most prestigious architects competed for a chance to redesign the program of the structure, creating an urban landscape within the chaos of the city and providing space for sitting, eating, walking, biking, and outdoor amphitheaters, etc. This influenced the project in Chicago in many ways. The question arose as to what would happen if a similar program was intertwined with a modern mass transportation system. It also became important to consider innovative ideas to garner funding. Most transportation systems generally gain a small amount of profit from selling advertising space to different marketers. However, they often do a terrible job of it. Since this hypothetical project would renew the entire system, it became apparent that the new materiality or skin of this structure could be covered in advertising, generating a much greater amount of revenue. Using the most current technology, such as LED's or nanotechnology, would allow many advertisers to promote at the same time, multiplying the normal revenue. This, along with a modern suspended rail system, would maintain a correlation with the technical innovations happening in society currently, rather than creating a nostalgic resemblance to prior technology.
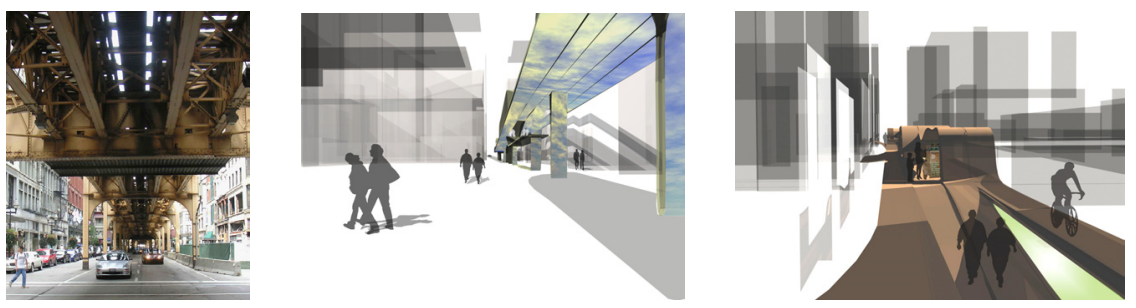

Figure 8: Current system deterioration compared with new concept.

The formal characteristics of the project stem from the idea of the ribbon and its connotation to the network of rail lines which weave through the city. The structure became a double ribbon system which intertwines in a constant flowing motion throughout the city. It is pulled and extruded in the vertical direction, creating the framework for columns below and covered retail or lounging space above. Analysis of the site context within the Loop became an integral part as the system begins to connect to various buildings making a seamless transition from the train to the station, up to the urban landscape and into the passenger's destination. The connections were chosen based upon the program and degree of usage within the building. Some of the connections open up in a horizontal direction to provide more space for public event space. Along with the intertwining of structure, perforations are made in the top plane to allow deposits of light to the ground plane. The point of this project is not to pull people from ground level pedestrian activity and business, but to provide an urban oasis for the tourists, workers, students and residents within the area, while providing an interesting transit experience for the whole community. 


\section{Conclusion}

The five intercultural and international case studies show that urban infrastructure can be approached as an interdisciplinary collaborative engineering/architectural/marketing/urban/landscape challenge, which by giving it a meaning beyond the single discipline, can create a vital contribution to a future mobile society. Regarding the conference topic category of economic and social impact, it seems that if the design process itself is sensitively responsive to these criteria, the resulting design has a good chance to be socially accepted and only by that does it economically succeed. In particular, the youngest, currently educated generation of infra-scape designers, like Mumm demonstrates in this paper, will push the level way beyond their teacher's ability [8], towards a holistic revolution of urban transportation, because they discover that to get people to progressively move, one has to sensually and emotionally move them on an individual basis.

\section{References}

[1] Peter, B. L., Ashgate Wittgensteinian Studies, Aldershot Hampshire: Ashgate Publishing Ltd, 2004

[2] www.despangarchitekten.de

[3] http://archweb.unl.edu

[4] Selected awards and honorable mentions: Architekturpreis Metalldaecher und Fassaden (architectural award for metal roofs and facades), Germany, 2000 / ar $+d$ emerging architecture award 1999, UK, 1999 / German Urban Award (Deutscher Staedtebaupreis), Germany, 1999

[5] Selected publications: Ballard Bell V. with Patrick R., Materiality for design, New York, Princeton Architectural Press, 2006 [7]/ Area Infrascape, Milano Italy, 42005 / C3, Seoul Korea, 122004 / Spiess F. et Vincent J.L., Chantier ouvert au public, Paris, 2005 / Bahamon A., Prefab, Barcelona, Loft Publications, 2002 / Richardson P., XS:Big Ideas, small Buildings", London, Thames \& Hudson, 2001 / Zoo, London, 6/2000Arquitetura \& Urbanismo, Sao Paulo Brasil, 72001 / Pasajes de arquitectura y critica, Madrid Spain, 92000 /Wallpaper, London UK , 5 2000 / Architectural Review, London, UK, $111999+121999$ / Rivista Tecnica, Lugano Switzerland, 62000 / Architektur + Technik, Schlieren Switzerland, 52000 / ,architektur“, Perchtoldsdorf Austria ,6 2000 / Architektur Aktuell, Wien Austria, 1-2 2000 /Detail, Germany, 42000 / Baumeister Germany, 31999 / Bauwelt, 101999 / DBZ, Germany, 10 1999

[6] Collis H., Transport, Engineering and Architecture" London, Laurence King Publishing Ltd, 2003

[7] Leonhardt U., Picasso's Stierkopf, DBZ 112002

[8] Area 79, Infrascape, Milano, 042005

[9] www.erinmumm.com 